First publ. in: Journal of Occupational and Organizational Psychology (JOOP) 82 (2009), pp. 575-594

\title{
Does work engagement increase after a short respite? The role of job involvement as a double-edged sword
}

\author{
Jana Kühnel ${ }^{\prime *}$, Sabine Sonnentag' and Mina Westman ${ }^{2}$ \\ 'University of Konstanz, Konstanz, Germany \\ ${ }^{2}$ Tel Aviv University, Tel Aviv, Israel
}

\begin{abstract}
This study extends research on work engagement by examining how a short respite and general job involvement contribute to work engagement. We gathered questionnaire data from 156 nurses before and after a short respite. Results indicated an increase of work engagement after the respite. Structural equation modelling showed that nurses who experienced psychological detachment from work during the respite showed a higher increase of work engagement. Moreover, nurses who indicated higher job involvement also showed a higher increase of work engagement. Contradictory to this direct positive effect job involvement had on change in work engagement, job involvement exerted a negative indirect effect on change in work engagement by impaired psychological detachment during the respite. Hence, job involvement acted as a double edged sword for the increase of work engagement. Practical implications for the organization of short respites and suggestions for future research on recovery processes are discussed.
\end{abstract}

There is increasing empirical evidence that vacations, weekends, and other respites that provide opportunities to recover from work result in a decrease in burnout (Fritz \& Sonnentag, 2006; Westman \& Eden, 1997) and perceived stress from work (Westman \& Etzion, 2001). Besides enabling relief of negative consequences of work, vacations and other respites enhance positive states at work such as well-being (Eden, 2001) and effort expenditure (Fritz \& Sonnentag, 2006). Extending these earlier findings, the purpose of this study is to examine the effect of a short respite from work on work engagement, a positive state of mind at work.

Research has shown that work engagement is relevant for outcomes such as low turnover intention (Schaufeli \& Bakker, 2004), high organizational commitment (Demerouti, Bakker, de Jonge, Janssen, \& Schaufeli, 2001; Hakanen, Bakker, \& Schaufeli, 2006; Richardsen, Burke, \& Martinussen, 2006), positive affect at work (Rothbard, 2001), and customer-rated employee performance (Salanova, Agut, \& Peiró, 2005).

* Correspondence should be addressed to Jana Kühnel, Department of Psychology, Work and Organizational Psychology, Postbox 42, University of Konstanz, 78457 Konstanz, Germany (e-mail: jana.kuehnel@uni-konstanz.de). 
In the light of the relevance of these outcomes for organizations and individuals alike, it is worth to identify factors that increase work engagement.

The conservation of resources (COR) theory (Hobfoll, 1998, 2001) serves as a general theoretical framework for this study. COR theory suggests that resources of the individual are threatened when the individual is confronted with demands during stressful work. Resources can be restored by removing the demands during time periods such as work breaks or respites that allow for such a restoration of resources. We adapted the COR theory because this study deals with the restoration of resources during a short respite and the investment of restored resources into the job after a short respite.

In our study, short respites refer to periods between 2 and 4 days off the job. The focus on such short respites enables us to examine effects of a recovery period such as a long weekend in demarcation to daily recovery and to longer recovery periods such as vacations. According to Eden (2001), research on the role of short respites such as weekends is still rare (for an exception see Fritz \& Sonnentag, 2005). Besides examining effects of a short respite by itself on work engagement, the aim of this study is to add to research on recovery by taking into account psychological detachment from work as one important experience during the respite and by taking into account job involvement as one characteristic of the individual. Psychological detachment from work refers to an individual's experience of being mentally away from work during off-job time (Etzion, Eden, \& Lapidot, 1998; Sonnentag \& Fritz, 2007). We focus on this recovery experience because it turned out to be crucial for recovery (Sonnentag \& Bayer, 2005). We also consider job involvement, a relatively stable attitude to one's job (Kanungo, 1982). Up to now, little attention has been paid to the question how attitudes to one's job are related to recovery experiences during off-job time. We want to address this gap by examining if and how job involvement indirectly exerts influence on work engagement through fostering or hindering psychological detachment during a short respite. To our knowledge, this is the first study which simultaneously took into account both possible positive and possible negative effects of job involvement on work engagement.

In the following, we first outline why we expect a short respite to have a beneficial impact on work engagement. We then explain our conceptual model which shows how psychological detachment during a short respite and job involvement are related to change in work engagement from before to after a short respite.

\section{Recovery and work engagement}

Work engagement is defined as a positive, fulfilling, work-related state of mind that is characterized by vigour, dedication, and absorption (González-Romá, Schaufeli, Bakker, \& Lloret, 2006; Maslach, Schaufeli, \& Leiter, 2001; Schaufeli, Bakker, \& Salanova, 2006). Vigour refers to high levels of energy and mental resilience while working, the willingness to invest effort in one's work, and persistence even in the face of difficulties. Dedication refers to being strongly involved in one's work and experiencing a sense of significance, enthusiasm, inspiration, pride, and challenge. The third component of work engagement, absorption, is characterized by being fully concentrated and engrossed in one's work, whereby experiencing that time passes quickly.

According to Kahn (1990), physical, emotional, and psychological resources are a necessary prerequisite for showing work engagement. Thus, gaining resources should facilitate individuals to experience work engagement. COR theory (Hobfoll, 1989, 2001) suggests that individuals who are not well recovered may tend to withdraw from work demands to protect their resources and to avoid further loss of resources, for example 
by showing absenteeism (Westman \& Etzion, 2001). Individuals who are recovered will have more resources available than less recovered individuals and do not have to withdraw from work demands in order to protect their resources. We thus conclude that a short respite should have positive effects ${ }^{1}$ on the experience of work engagement. In a daily survey study, Sonnentag (2003) showed that feeling recovered in the morning was positively related to work engagement during the subsequent work day. These findings underpin that daily recovery and the associated restoration of resources help individuals to experience work engagement. Also recovery during a longer time period such as a short respite should support individuals to experience work engagement.

Hypothesis 1: Work engagement will increase after a short respite from work.

\section{Overview of the research model}

Figure 1 displays our conceptual model that takes into account job involvement and psychological detachment from work as predictors of change in work engagement from before to after a short respite.

\section{Psychological detachment and work engagement}

A psychological experience crucial for recovery from job stress is psychological detachment from work during off-job time (Etzion et al., 1998; Kühnel, 2005; Sonnentag \& Bayer, 2005). Psychological detachment refers to an individual's experience of being mentally away from work during off-job time, that is 'switching off' mentally from work. The effort-recovery model (Meijman \& Mulder, 1998) states that confrontation with work demands requires effort expenditure which leads to reversible load reactions such as physiological activation and fatigue. When work demands are removed from the individual, the load reactions are reversed, recovery can occur (Craig \& Cooper, 1992), and resources called upon during work can be rebuilt (Hobfoll, 1989, 2001). Such resources, for instance, include energy (Hobfoll, 1998) or self-regulatory resources (Muraven \& Baumeister, 2000). Research indicates that energetic resources enable individuals to capitalize on opportunities for goal enhancement (Zohar, Tzischinsky, Epstein, \& Lavie, 2005) and that self-regulatory resources impact on individuals' ability to regulate behaviour at work (Trougakos, Beal, Green, \& Weiss, 2008).

However, when the job is cognitively present during the time off the job, work demands and potential stressors remain present (Brosschot, Pieper, \& Thayer, 2005) and could lead to prolonged physical activation and to health complaints in the long run (for a review see Geurts \& Sonnentag, 2006). We propose that psychological detachment ensures the mental removal of work demands. When work demands are removed mentally from the individual, resources called upon during work can be rebuilt (Hobfoll, 1989, 2001). Subsequently, these resources are available at work and help individuals to show work engagement.

Hypothesis 2: Psychological detachment during a short respite will be positively related to change in work engagement from before to after a short respite.

\footnotetext{
' We use the statistical terminology to explain the hypothesized pattern of relationships between job involvement, psychological detachment, and work engagement and thus refer to effects. We want to emphasize that we are aware of the fact that the relationships presented here are correlational in nature.
} 


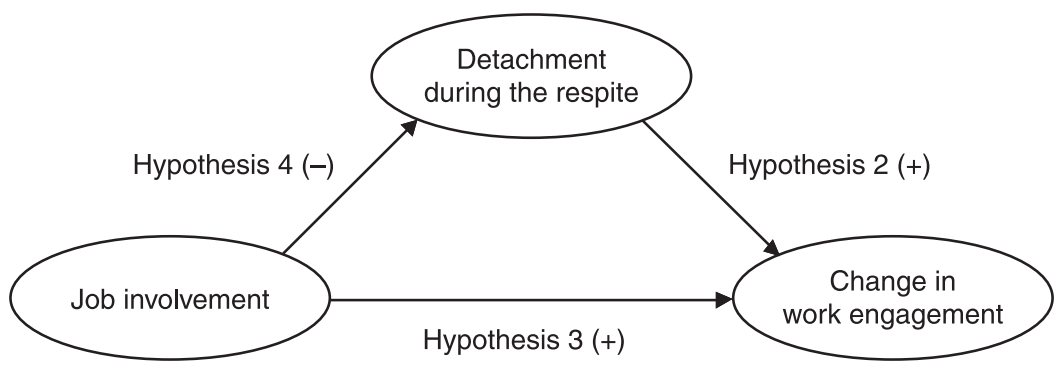

Figure I. Conceptual model. Note. Signs in parentheses indicate a positive $(+)$ or a negative ( ) relationship.

We want to emphasize that psychological detachment refers to an experience during off-job time while work engagement refers to a motivational state at work. Thus, we propose that an off-job experience that fosters the restoration of resources is crucial for 'being charged with energy' at work and being 'fully dedicated to one's work' (Hallberg \& Schaufeli, 2006, p. 119). Experiencing vigour, dedication, and absorption at work does not imply that one shows continued cognitive engagement with one's work during off-job time. Although the third dimension of work engagement, absorption, is defined as 'being fully concentrated and engrossed in one's work, whereby time passes quickly and one has difficulties with detaching oneself from work' (Schaufeli, Salanova, González-Romá, \& Bakker, 2002), the last passage in the definition refers to detaching oneself from work while working. Work engagement is thus not characterized by a reluctance to disengage from work during off-job time. Also Macey and Schneider (2008) recently suggested that in order to remain engaged, people cannot continuously expend their energy at highest levels, that is showing engagement in work all the time. Particularly highly engaged employees need recovery from work, in other words they need to psychologically detach when not being at work.

\section{Job involvement and work engagement}

The availability of resources after a short respite does not necessarily imply that these resources are invested into work. Individuals may differ in their willingness to invest resources they gained during a short respite into the job. A relatively stable job attitude that might influence the investment of resources is job involvement. Job involvement is defined as a 'cognitive belief state of psychological identification' with one's job (Kanungo, 1982, p. 80). Highly job-involved individuals have been hypothesized to contribute substantial effort towards the achievement of organizational objectives, while low job-involved individuals have been hypothesized to withdraw effort from the job (Kanungo, 1979). Differentiating job involvement from work engagement, Hallberg and Schaufeli (2006) concluded that both are empirically distinct constructs which reflect different aspects of work attachment. Work engagement is conceptualized as optimal functioning of the individual at work (Hallberg \& Schaufeli, 2006), while job involvement is defined as a cognitive, specific belief regarding one's relationship with one's job (Kanungo, 1982). In this study, job involvement is considered as a relative stable job attitude, a cognitive judgment about the need satisfying abilities of the job, whereas work engagement is considered as the experience of vigour, dedication, and absorption at work that can fluctuate from day to day (Dalal, Brummel, Wee, \& Thomas, 2008).

In line with the COR framework (Hobfoll, 1989), individuals are willing to invest other resources in order to gain valued resources. Highly job-involved individuals 
perceive their job to meet salient needs (Kanungo, 1982, p. 66), in other words they consider their job suitable for gaining valued resources. Therefore, we propose that they should be willing to invest more resources into the job than less job-involved individuals. Research revealed positive relationships between job involvement and the investment of resources such as expending time and effort (Brown \& Leigh, 1996; Paterson \& O'Driscoll, 1990). We hypothesize that investment of resources into the job is also reflected in the experience of work engagement. As highly job-involved individuals show a greater investment of resources into the job than less job-involved individuals, we therefore propose that high job involvement becomes apparent in a greater increase of work engagement from before to after a short respite for highly jobinvolved individuals than for less job-involved individuals.

Hypothesis 3: Job involvement will be positively related to change in work engagement from before to after a short respite.

Besides this possible beneficial effect of job involvement, possible negative effects of job involvement have to be taken into account, too. As proposed above, highly jobinvolved individuals are considered as being willing to invest more resources into the job than less job-involved individuals. In line with this, highly job-involved individuals may think more about their work during off-job time, that is investing cognitive resources in their work. But continuously demanding resources that were called upon during work may hamper the restoration of these resources during off-job time (Hobfoll, 1989; Meijman \& Mulder, 1998). A recent study from Sonnentag and Kruel (2006) disclosed that highly job-involved individuals showed less psychological detachment from their jobs during off-job time. This negative relationship between job involvement and psychological detachment renders it likely to consider lack of psychological detachment as a possible process by which high job involvement can entail negative costs. Research revealed positive relationships between job involvement and poor mental health (Kanungo, 1982) and job-induced tension (Cohen, 1998). In addition, Frone, Russell, and Cooper (1995) discovered that job involvement represents a vulnerability factor that exacerbates the relationship between job stressors and employee health. We therefore propose that high job involvement may hamper the restoration of resources during off-job time due to its supposed negative effect on psychological detachment during off-job time. With respect to the present study, hampered restoration of resources during a short respite should become apparent in reduced work engagement after the respite.

Hypothesis 4: Job involvement will be negatively related to psychological detachment during the respite.

We emphasize that psychological detachment during off-job time has to be conceptually distinguished from work engagement and job involvement. As described above, the experience of engagement at work does not imply a reluctance to disengage from work during off-job time. Conceptually, being highly job-involved must not be equated with a lack of psychological detachment from the job during off-job time, although we expect a negative empirical relationship between high job involvement and psychological detachment. We agree with Hallberg and Schaufeli (2006), Schaufeli, Taris, and Bakker (2006), and Schaufeli, Taris, and van Rhenen (2008) that highly jobinvolved individuals and individuals who experience high work engagement not necessarily 'persistently and frequently think about work, even when not working' (Schaufeli et al., 2007, p. 3). 
To sum up, we propose that job involvement should show an overall positive effect on change in work engagement. As stated in Hypothesis 3, job involvement should be positively related to change in work engagement because highly jobinvolved individuals are willing to invest more resources into the job than less job-involved individuals. Of course, investment of resources requires availability of resources. Psychological detachment should foster the restoration of resources during a short respite which should be reflected in a positive relationship between psychological detachment and change in work engagement (Hypothesis 2). As proposed above, highly job-involved individuals face the risk of lacking psychological detachment which hampers the restoration of resources called upon during work (Hypothesis 4). Therefore, contradictory to the hypothesized direct positive effect of job involvement on change in work engagement (Hypothesis 3), job involvement may also have a negative indirect effect on change in work engagement by impaired psychological detachment. Hence, job involvement may act as a doubleedged sword for the increase of work engagement: we propose a direct positive and an indirect negative effect of job involvement on change in work engagement that coexist. The direct positive and the indirect negative effect should result in an overall positive effect of job involvement on change in work engagement that is smaller than the direct positive effect due to the indirect negative effect via psychological detachment.

Such a partial mediation pattern where the direct and the indirect effect have opposite signs is labelled 'inconsistent mediation' or 'suppression situation' (Davis, 1998; MacKinnon, Krull, \& Lockwood, 2000; Shrout \& Bolger, 2002). A partial mediation pattern is given when a predictor variable has both a direct effect on an outcome variable and an indirect effect on an outcome variable via a mediating variable. The direct and the indirect effect result in an overall effect of the predictor variable on the outcome variable. Thus, the overall effect of a predictor variable on an outcome variable is partially explained by the mediating variable. This mediation pattern is labelled 'inconsistent', when the direct and the indirect effect of the predictor variable on the outcome variable are contradictory, that is have opposite signs. For example, this is the case when a predictor variable exhibits both a positive direct effect and a negative indirect effect on the outcome variable. As the resulting overall effect of the predictor variable on the outcome variable is the sum of the positive direct effect and the negative indirect effect, these effects can override each other. In our study, job involvement is proposed to be a predictor variable that exhibits both a positive direct effect on change in work engagement and a negative indirect effect on change in work engagement via impaired psychological detachment.

We explicitly propose mediation and not moderation, because we do not assume that the effect of psychological detachment on work engagement changes depending on the level of job involvement. Similarly, we do not assume that the effect of job involvement on work engagement changes depending on the level of psychological detachment. Rather, we propose that the impact of job involvement on work engagement is twofold: positive because of the willingness to invest more than average into the job and negative because of the accompanying risk of worse restoration of resources during off-job time.

Hypothesis 5: Job involvement will have a negative indirect effect on change in work engagement via psychological detachment. 


\section{Method}

\section{Sample}

Nurses from hospitals in Germany and Switzerland participated in the study. To recruit study participants, we approached Chief Nurse Executives and informed them about the study. After they agreed to participate, we sent information about the study and application forms to staff members. Nurses who applied for participation by sending back the application form received survey packages. Survey packages included an information letter, two questionnaires and a stamped return envelope preaddressed to the researchers at the university. The information letter introduced the study as research on 'recovery during the weekend' and emphasized voluntariness and confidentiality of responses. The information letter also stressed that 'weekend' refers to periods between 2 and 4 days off the job and that due to shiftwork of nurses the days off the job did not necessarily have to include Saturday and Sunday. To enhance participation, we promised feedback about the study and later sent feedback to Chief Nurse Executives and participating nurses.

We sent out 260 survey packages. A total of 207 employees returned questionnaires (response rate of 79.6\%). We included only questionnaires from respondents who had at least 2 but not more than 4 days off to examine effects of a recovery period such as a long weekend in demarcation to daily recovery and to longer recovery periods such as vacations. We took measures to control if participants filled out the surveys at the instructed points in time: we asked for current date and current day of week in both surveys and for number of days off the job and which days of the week they had off in the second survey. We checked congruity of information and excluded participants who did not follow the instructions. The final sample consisted of 156 employees who provided complete data (overall response rate: 60\%). The majority of the respondents were women (85.9\%). About $81 \%$ of the participants worked in Germany, $19 \%$ worked in Switzerland. Average age was 38.7 years ( $S D$ 10.2). About $35 \%$ of the participants had children. Participants' job experience ranged between less than 1 year and 38 years ( $M \quad 15.8$ years). Weekly work hours ranged from 16 to 40 hours ( $M \quad 37.0$ ).

\section{Measures}

We gathered data with two questionnaires. Participants had to complete the first questionnaire at the end of the last working day before the short respite (Time 1) and the second questionnaire at the end of the first working day after the short respite (Time 2). Job involvement and control variables were measured before the short respite (Time 1); psychological detachment during the short respite was measured retrospectively after the short respite (Time 2). Work engagement was measured at both points of measurement. All items were in German.

\section{Work engagement}

We assessed work engagement with the nine-item version of the Utrecht Work Engagement Scale devised by Schaufeli et al. (2006), slightly adapted to measure work engagement during the working day. Items had to be answered on a 7-point Likert scale ranging from 0 (strongly disagree) to 6 (strongly agree). Sample items were 'Today, I felt bursting with energy at work' and 'Today, I felt strong and vigorous at work'. Cronbach's $\alpha$ was .93 and .95 for Time 1 and Time 2, respectively. 
Job involvement

We assessed job involvement with eight items from a measure developed by Kanungo (1982). Items had to be answered on a 5-point Likert scale ranging from 1 (strongly disagree) to 5 (strongly agree). A sample item was: 'I am very much involved personally in my job'. Cronbach's $\alpha$ was .89 .

\section{Psychological detachment}

We measured psychological detachment with four items adapted from the recovery experience questionnaire developed by Sonnentag and Fritz (2007). Items had to be answered on a 5-point Likert scale ranging from 1 (strongly disagree) to 5 (strongly agree). Sample items were: 'During the days off, I didn't think about work at all' and 'During the days off, I gained distance to my job requirements'. Cronbach's $\alpha$ was .86 .

One might argue that work engagement, job involvement, and psychological detachment show substantial conceptual overlap. Therefore, we conducted confirmatory factor analyses (CFAs) with the items of work engagement assessed at Time 2 and the items of job involvement and psychological detachment. Results from CFAs revealed that the three-factor model with a $\chi^{2}$ of 375.9 ( $d f$ 186, RMSEA .081, CFI .916, NNFI .906) fitted the data better than the best fitting two-factor model

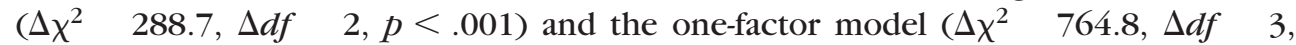
$p<.001)$. Although the fit index RMSEA for the three-factor model is slightly above the recommended cut-off value of .080 (Browne \& Cudeck, 1993), the overall pattern of findings suggests that psychological detachment, job involvement, and work engagement are distinct constructs.

\section{Control variables}

At Time 1 we measured a number of additional variables (gender, age, number of children, weekly work hours, and dispositional negative affectivity) that we took into account in the structural equation models. We assessed dispositional negative affectivity because negative affectivity may account for shared variance between our outcome variable on the one hand and psychological detachment and job involvement on the other hand (Podsakoff, MacKenzie, Lee, \& Podsakoff, 2003). Specifically, we measured negative affectivity with the 10 negative affect items from the PANAS (Watson, Clark, \& Tellegen, 1988). Cronbach's $\alpha$ was .86.

\section{Data analysis}

To test Hypothesis 1, we computed a $t$-test for paired samples to examine the difference in work engagement measured before the short respite (Time 1) and after the short respite (Time 2). To test Hypotheses 2-5, we modelled the hypothesized relationships with structural equation modelling as implemented by AMOS (Arbuckle, 2006) with items respectively parcels as observed indicators of the latent variables work engagement at Time 2, job involvement and psychological detachment.

We parcelled the eight job involvement items and the nine work engagement items because of the psychometric merits of parcels relative to items (e.g. smaller likelihood of distributional violations, greater ratio of common-to-unique factor variance; Little, Cunningham, Shahar, \& Widaman, 2002) and because we wanted to improve the variable-to-sample-size ratio (Nunnally \& Bernstein, 1994). As recommended by Little et al. (2002) and others (e.g. Holt, 2004) we first computed an exploratory factor 
analysis with oblimin rotation to examine the factor structure of the job involvement items to be parcelled. The factor analysis of the eight items showed that the items represent a unidimensional construct (one factor was extracted, explaining $50.7 \%$ of the variance). Subsequently, we parcelled the job involvement items by randomly allocating the eight items into two parcels. More specifically, we formed two parcels with four items each, instead of four parcels with two items each, to follow the recommendations of Holt (2004) that favour a smaller number of parcels with more items each. Cronbach's $\alpha$ was .80 and .78 for Parcel 1 and Parcel 2, respectively. Schaufeli et al. (2002) and Schaufeli et al. (2006) showed that work engagement has a three-factor structure with the facets vigour, dedication, and absorption. Because work engagement is not unidimensional, we used the isolated parcelling strategy as was recommended by Holt (2004) and Bagozzi and Heatherton (1994). We parcelled together the three items of the subscale vigour (Cronbach's $\alpha$ was .80 and .84 for Time 1 and Time 2, respectively), the three items of the subscale dedication (Cronbach's $\alpha$ was .84 and .89 for Time 1 and Time 2, respectively), and the three items of the subscale absorption (Cronbach's $\alpha$ was .87 and .92 for Time 1 and Time 2, respectively). We did not parcel the psychological detachment scale because it consisted of four items only.

To take into account the control variables gender, age, number of children, weekly work hours, and trait negative affectivity, we ran regression analyses predicting each of the observed indicators of the model from the control variables. The residuals of these regression analyses were used as input for subsequent structural equation modelling. Shared variance between our control variables and the residualized indicators is thus not included in the model. Following the same logic, work engagement before the short respite (Time 1) was also a predictor in the regression analyses. Thus, shared variance between work engagement at Time 1 and the residualized indicators is not included in the model. As we statistically controlled for the level of work engagement before the short respite, the residualized indicators of work engagement at Time 2 represent the change in work engagement from before to after the short respite. Thus, we labelled the latent variable 'change in work engagement'.

Following Baron and Kenny (1986), Judd and Kenny (1981), and MacKinnon (2003), we built three models that equalled the three steps of testing a mediation model. In Model 1 , the predictor (job involvement) was assumed to be related to the outcome (change in work engagement), and the relationships between the predictor (job involvement) and the mediator (psychological detachment) and between the mediator (psychological detachment) and the outcome (change in work engagement) were constrained to zero. In Model 2, the predictor (job involvement) was assumed to be related to the mediator (psychological detachment), and the relationships between the mediator (psychological detachment) and the outcome (change in work engagement) and between the predictor (job involvement) and the outcome (change in work engagement) were constrained to zero. Model 3 is the full model relating the predictor (job involvement) to the outcome (change in work engagement) adjusted for the mediator (psychological detachment). Model 1 is nested in Model 3 and Model 2 is nested in Model 3.

\section{Results}

\section{Descriptive analyses}

Table 1 shows means, standard deviations, internal consistencies, and intercorrelations of variables. As expected, job involvement was positively related to work engagement before (Time 1) and after (Time 2) the short respite and negatively related to 
Table I. Means, standard deviations, internal consistencies, and intercorrelations

\begin{tabular}{|c|c|c|c|c|c|c|c|c|c|c|c|}
\hline Variable & M & SD & $\alpha$ & 1 & 2 & 3 & 4 & 5 & 6 & 7 & 8 \\
\hline I. Job involvement & 2.90 & 0.77 & .89 & & & & & & & & \\
\hline 2. Psychological detachment & 3.53 & 1.08 & .86 & $.24 * *$ & & & & & & & \\
\hline 3. Work engagement (TI) & 3.36 & 1.18 & .93 & $.32 * * *$ & .02 & & & & & & \\
\hline 4. Work engagement (T2) & 3.58 & 1.25 & .95 & $.30 * * *$ & $.27 * *$ & $.51 * * * *$ & & & & & \\
\hline 5. Negative affectivity & 2.05 & 0.73 & .86 & .07 & $.27 * *$ & $.36 * * *$ & $.40 * * *$ & & & & \\
\hline 6. Gender & - & - & - & .03 & .02 & .03 & .02 & .01 & & & \\
\hline 7. Age & 38.71 & 10.20 & - & .13 & .12 & .15 & .03 & .03 & .10 & & \\
\hline 8. Number of children & 0.71 & 1.12 & - & .07 & .08 & .13 & .04 & .03 & $.22 * *$ & $.44 * * *$ & \\
\hline 9. Weekly work hours & 37.04 & 5.59 & - & $.19 *$ & .02 & .03 & .01 & .01 & .15 & $.24 * *$ & .14 \\
\hline
\end{tabular}

$N=$ I56. Note. $\mathrm{TI}=$ Time I, before the short respite; $\mathrm{T} 2=$ Time 2 , after the short respite. Gender: I = female; $2=$ male. $* p<.05 ; * * p<.01 ; * * * *$ p $<.001$. 
psychological detachment during the short respite. In line with the hypotheses, psychological detachment was positively related to work engagement after the short respite and not related to work engagement before the short respite. Furthermore, negative affectivity showed substantial negative correlations with three of the core variables of interest (i.e. psychological detachment and work engagement at both points of measurement).

\section{Testing the research model}

First, we computed a $t$-test for paired samples to examine the difference in work engagement measured at Time 1 ( $M$ 3 3.36) and Time 2 ( $M$ 3.58). The result $(t \quad 2.23, d f \quad 155, p<.05)$ indicated that work engagement increased significantly after the short respite and thus provided support for Hypothesis 1.

To test Hypotheses 2-5, we built three models that equalled the three steps of testing a mediation model following Baron and Kenny (1986), Judd and Kenny (1981), and MacKinnon (2003). In the first step (Model 1), we computed the structural coefficient $\tau$ relating the predictor (job involvement) to the outcome (change in engagement). The

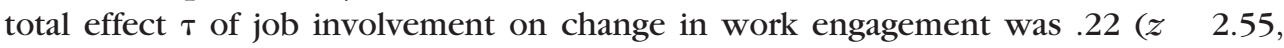
$p<.05$ ), providing support for Hypothesis 3. In the second step (Model 2), we computed the structural coefficient $\alpha$ relating the predictor (job involvement) to the mediator (psychological detachment). The structural coefficient $\alpha$ relating job involvement to psychological detachment was $.27(z \quad 3.17, p<.01)$, providing support for Hypothesis 4. In the final step (Model 3), we computed the structural coefficient $\tau^{\prime}$ relating the predictor (job involvement) to the outcome (change in work engagement) adjusted for the mediator. The direct effect $\tau^{\prime}$ of job involvement on change in work engagement was $.32(z \quad 3.69, p<.001)$. The structural coefficient $\beta$ relating psychological detachment to change in engagement was .36 ( $z \quad 4.02$, $p<.001$ ), providing support for Hypothesis 2 .

Figure 2 shows the standardized estimates of the structural coefficients $\alpha, \beta$, and $\tau^{\prime}$ in Model 3. A Sobel test (Sobel, 1982) showed the significance of the indirect effect $\alpha \beta$ of

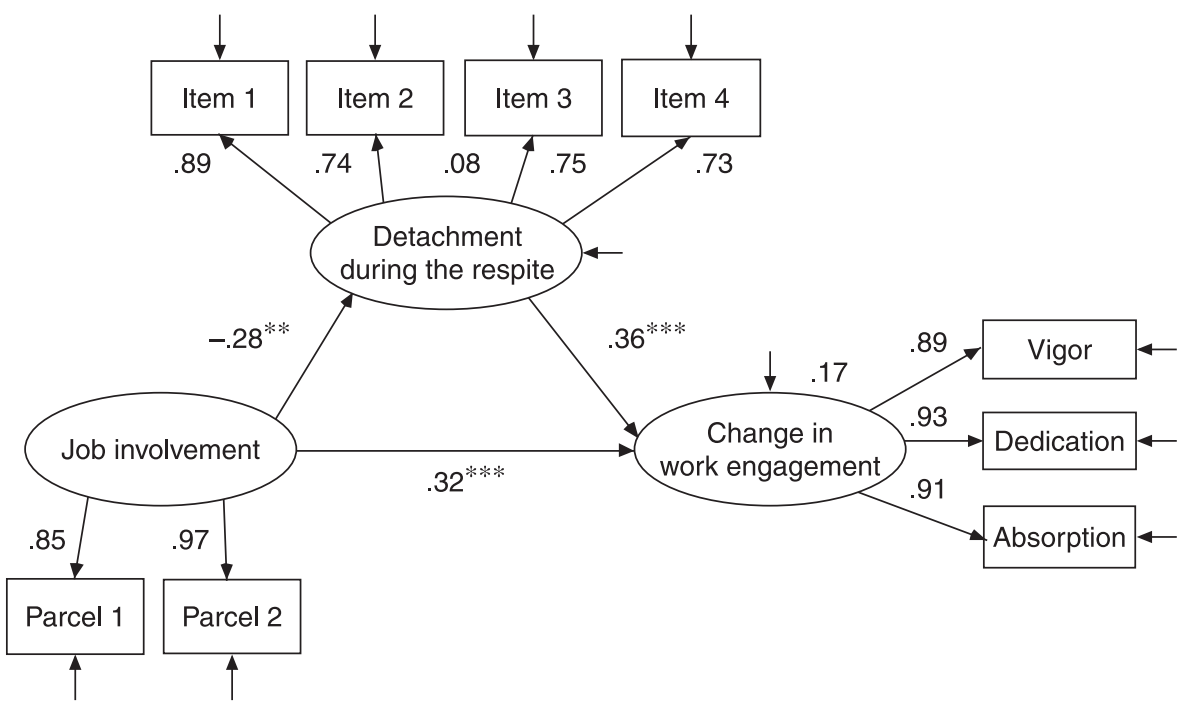

Figure 2. Statistical estimates for the conceptual model. Note. $* p<.05 ; * * p<.0$ I; $* * * p<.00$ I. 


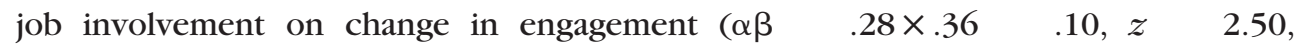
$p<.05)$. To follow recent recommendations of Cheung and Lau (2008), we additionally calculated bias-corrected bootstrap confidence intervals. In their simulation and in simulations of Fritz and MacKinnon (2007) these confidence intervals performed best in testing mediation effects. The AMOS output for 1,000 bootstrap samples showed that the estimated indirect effect $\alpha \beta$ from job involvement to change in engagement was

.104 . The lower bound of the $95 \%$ bias-corrected confidence interval for the indirect effect was .215 , the upper bound was .031, with a $p$-value at .005 for two-tailed significance test. The sum of the indirect effect $\alpha \beta$ and the direct effect $\tau^{\prime}$ equals the total effect $\tau\left(\begin{array}{lll}\tau & \alpha \beta+\tau^{\prime} & \text {.22) of job involvement on change in engagement. Taking }\end{array}\right.$ into account the mediator reduces the total effect $\tau$ by the amount of the indirect effect $\alpha \beta\left(\begin{array}{lll}\tau^{\prime} & \tau & \alpha \beta\end{array}\right)$. Therefore, usually the coefficient $\tau^{\prime}$ is smaller than the coefficient $\tau$ and becomes zero when the indirect effect fully accounts for the total effect (full mediation model). Because our model is dealing with inconsistent mediation, the indirect effect has a negative sign whereas the direct effect has a positive sign. Therefore, the coefficient $\tau^{\prime}$ is not decreased, but is increased, in Step $3\left(\tau^{\prime} \quad \tau \quad \alpha \beta\right.$; $\left.\begin{array}{llll}\tau^{\prime} & .22 & (.10) & .32\end{array}\right)$

Table 2 shows fit indices of the models. Model $3\left(\begin{array}{llll}\chi^{2} & 24.1, d & 24, p & .44\end{array}\right)$ fitted

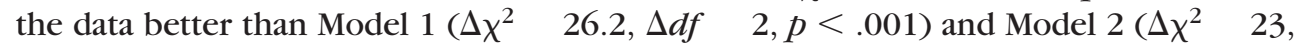
$\Delta d f \quad 2, p<.001$ ), with all fit indices meeting the recommended criteria. The $p$-value of Model 3 indicated that the departure of the data from the model was not significant. The measures of overall fit were the goodness-of-fit index (GFI .967), the adjusted goodness-of-fit index (AGFI .938), the root mean square error of approximation (RMSEA .009), and the standardized root mean square residual (SRMR .033). We further computed the normed fit index (NFI .973), the non-normed fit index (NNFI .999), the comparative fit index (CFI 1.000), and the incremental fit index (IFI 1.000). In sum, fit indices were best for Model 3 and indicated a very good fit of the model to the data.

To sum up, the requirements of the three steps to establish mediation were met, the tests of the indirect effect were significant, and the fit indices indicated a good fit of Model 3. Thus, results revealed support for Hypothesis 5.

\section{Discussion}

In this study, we examined the increase of work engagement during a short respite. We were particularly interested in the inconsistent effects of job involvement on change in work engagement. Specifically, we proposed that job involvement is positively related to change in work engagement. Contradictory to this direct positive effect of job involvement, we also proposed that high job involvement should have a negative indirect effect on change in work engagement due to diminished psychological detachment during the short respite.

Our results suggest that work engagement is affected by experiences during off-job time. Analyses showed that psychological detachment during the short respite significantly predicted change in work engagement from before to after the respite with nurses who experienced more psychological detachment showing a higher increase in work engagement. This finding is consistent with the assumption that the physical and psychological removal of work-related demands allows individuals to restore depleted resources (Hobfoll, 1989, 2001; Meijman \& Mulder, 1998) which then become apparent in an enhancement of positive states at work. 
Table 2. Model fit $(N=156)$

\begin{tabular}{llllllllllll}
\hline Model & $\chi^{2}(\mathrm{df})$ & $\mathrm{p}$ & GFI & AGFI & RMSEA & SRMS & NFI & NNFI & CFI & IFI & Coefficients \\
\hline MI: Step I & $50.5(26)$ & .003 & .933 & .885 & .078 & .134 & .944 & .961 & .972 & .972 & $\tau=.22^{*}$ \\
M2: Step 2 & $47.1(26)$ & .007 & .940 & .896 & .072 & .124 & .943 & .966 & .976 & .976 & $\alpha=.27^{* *}$ \\
M3: Step 3 & $24.1(24)$ & .444 & .967 & .938 & .009 & .033 & .973 & .999 & 1.000 & 1.000 & $\beta=0.36^{* * *} ; \tau^{\prime}=.32^{* * *}$ \\
\hline
\end{tabular}

$N=156$. Note. $\chi^{2}$, Chi square; $d f$, degrees of freedom; GFl, goodness of fit index; AGFl, adjusted goodness of fit index; RMSEA, root mean square error of approximation; SRMR, standardized root mean square residual; NFI, normed fit index; NNFI, non normed fit index; CFI, comparative fit index; IFI, incremental fit index; $\tau$, total effect of job involvement on change in work engagement; $\alpha$, effect of job involvement on psychological detachment; $\beta$, effect of psychological detachment on change in work engagement; $\tau^{\prime}$, direct effect of job involvement on change in work engagement.

$* p<.05 ; * * p<.01 ; * * * p<.001$. 
Our results further suggest that individual differences play a role in the willingness to invest restored resources into work. After the short respite, highly job-involved individuals showed a higher increase in work engagement than less job-involved individuals, that is highly job-involved individuals showed a greater investment of restored resources into work.

As hypothesized, contradictory to this direct positive effect of job involvement on change in work engagement, we also found a negative indirect effect of job involvement on change in work engagement. Because high job involvement was related to diminished psychological detachment during the respite, high job involvement had an indirect negative relationship to change in work engagement via diminished psychological detachment. Thus, this study suggests that job involvement is related to the experience of mental overlap between work and home: highly job-involved individuals showed less psychological detachment from their work during the short respite. As mentioned above, psychological detachment turned out to be crucial for the restoration of resources called upon during work. In other words, we showed that low psychological detachment is a possible mechanism by which high job involvement can entail negative costs. Therefore, we considered job involvement to have the role of a double-edged sword for the increase of work engagement during a short respite: on the one hand, highly job-involved individuals showed a higher increase of work engagement, that is they showed a greater investment of restored resources into work. On the other hand, high job involvement had the negative concomitant of decreased opportunity to recover from work-related demands and restoration of resources due to diminished psychological detachment. To the best of our knowledge, this is the first study which simultaneously took into account both positive and negative effects of job involvement. As described above, positive and negative effects override each other. Comparing the strengths of effects, we conclude that the direct positive effect $\left(\tau^{\prime} \quad .32\right)$ is stronger than the indirect negative effect $(\alpha \beta \quad$.10) because direct and indirect effect result in an overall effect that is positive $\left(\begin{array}{lll}\tau & \tau^{\prime}+\alpha \beta & .22\end{array}\right)$.

In this study, we conceptualized psychological detachment as an inconsistent mediator in the relationship between job involvement and change in work engagement. Alternatively, future studies might want to look at variables that work as moderators in the relationship between job involvement and work engagement. For example, lack of job resources such as low autonomy may work as a moderator insofar as the positive relationship between job involvement and work engagement may disappear when autonomy is low.

Our findings add to research on individual recovery, specifically on how the experience of work engagement benefits from a short respite. Fostering work engagement is of interest for individuals and organizations, because of its relevance for work outcomes and employee well-being (e.g. Hakanen et al., 2006; Rothbard, 2001). In this study, we could identify factors that foster the experience of work engagement: taking break from work for several days and experiencing psychological detachment from work during this break.

We hypothesized that distancing oneself from work during a short respite is beneficial for regeneration processes. However, we cannot conclude that not detaching from work is negative per se. Fritz and Sonnentag (2005) argued that staying connected and reflecting positively on one's job (e.g. thinking about a recent success) may replenish individual resources and thus enhance subsequent feelings of health and performance at work. They reported that positive work reflection during a short respite was negatively related to exhaustion and disengagement after a short respite and 
positively related to pursuit of learning after a short respite. Thus, although we found that detaching oneself psychologically from work seems to be important for individuals to restore depleted resources, reflecting positively on one's job can serve as an alternative way to replenish lost resources (Westman, 1999). Anyhow, regarding the positive relationship of psychological detachment and change in work engagement found in this study and based on other findings that revealed positive relationships between psychological detachment and well-being (Etzion et al., 1998; Sonnentag \& Bayer, 2005) and negative relationships between staying mentally connected to work and well-being and health (Aronsson, Svensson, \& Gustafsson, 2003; Thomsen, Mehlsen, Christensen, \& Zachariae, 2003) we are confident that negative correlates of low psychological detachment are more prevalent than positive ones.

We can rule out the alternative explanation that individuals with high and low job involvement had the same level of work engagement after the short respite and that the positive relationship between job involvement and the increase in work engagement is only due to the fact that highly job-involved individuals had a lower level of work engagement before the short respite than less job-involved individuals. The results presented in Table 1 do not support this view as job involvement and work engagement before a short respite (Time 1 ) were related positively $(r \quad .32, p<.001$ ). We thus conclude that highly job-involved individuals had a higher level of work engagement before the short respite and moreover showed an additional increase in work engagement after the respite. Thus, we assume that highly job-involved individuals generally maintain a higher level of work engagement than less job-involved individuals and that the former show greater fluctuations in daily work engagement due to short respites. We therefore think that further investigations of daily and weekly fluctuations in work engagement are important.

\section{Limitations}

As with any study, there are limitations to consider. The first limitation is the exclusive use of self-reports. Common method variance might have led to the inflation of relationships between the variables (Podsakoff et al., 2003). However, we used a longitudinal design with two measurement occasions and controlled for negative affectivity to weaken this argument. According to Podsakoff and colleagues (2003), variables measured at different points in time are less likely to suffer from common method bias. We controlled for dispositional negative affectivity because negative affectivity may account for shared variance between our outcome variable on the one hand and psychological detachment and job involvement on the other hand. Controlling for negative affectivity reduces the problems associated with common-method data because we can rule out negative affectivity as third variable explaining the findings (Podsakoff et al., 2003). We admit that we cannot completely rule out common method bias.

Furthermore, we think that the concepts studied here are operationalized most validly by self-report measures. Regarding job involvement, the meaning of the job in one's life cannot be evaluated by another person as good as by the target person him- or herself. Concerning work engagement, nurses face high workload and cannot pay attention to the state of their co-workers all the time. Finally, if one thinks about the job or does not think about job related issues can best be captured by asking the person about it, that is by self-report measures.

The second limitation is the potential conceptual overlap of the variables under study. However, we theoretically argued for the distinction of the concepts under study. 
Empirically, confirmatory factor analysis showed that psychological detachment, job involvement, and work engagement are distinct concepts. Furthermore, our variables referred to different time frames and levels of specificity, as we examined relationships between general job involvement, short respite-specific psychological detachment and the change in work engagement from before to after the short respite.

Third, researchers clearly need to examine the generalizability of our findings to other respites such as vacations and to day-specific recovery periods as well as to other employee groups. Our sample comprised nurses who had a short respite and did not pursue activities similar to their working activities during the respite. Future research might examine other employee groups who do part of their work at home, for instance teachers or teleworkers.

\section{Implications}

Several practical implications emerge from this study. To foster work engagement, individuals and organizations should pay attention to the issue of recovery during short respites. Concerning the organization of short respites, the following recommendations can be made: individuals should try to psychologically detach from work-related demands in order to restore resources called upon during working time. This goal could be achieved, for example, by engaging in distracting leisure activities which demand individuals' attention, by leaving off work consciously, and by avoiding taking work home. Organizations can support their employees to experience psychological detachment, for example by not contacting employees during non-work time. Furthermore, organizations should take care that individuals have sufficient recovery time at their disposal, for example by implementing regulations that restrict working overtime.

In addition to the importance of psychological detachment during non-work time, the present study revealed that highly job-involved individuals show more work engagement before the short respite and a higher increase of work engagement during the short respite. Thus, organizations should try to recruit highly job-involved individuals respectively try to meet salient needs of the employees to foster job involvement. This could be realized for example by ensuring that jobs have characteristics that are positively related to job involvement such as variety, autonomy, task identity, and feedback from the job itself (Rabinowitz, Hall, \& Goodale, 1977). As we know from this study, job involvement can act as a double-edged sword because high job involvement can have the negative concomitant of diminished psychological detachment during respites which may impair restoration of resources. Therefore, to increase the positive effect of job involvement on work engagement, individuals should take care of mentally detaching from work during off-job time and organizations should support their employees experiencing psychological detachment.

The present findings also have implications for future research. Future research should examine if and under which conditions low psychological detachment can have positive effects on work engagement. As mentioned above, reflecting positively on one's job can serve as an alternative way to replenish lost resources (Fritz \& Sonnentag, 2005; Westman, 1999). Furthermore, other recovery experiences which might influence the restoration and gain of resources such as mastery, relaxation, and control can be taken into account (Sonnentag \& Fritz, 2007).

\section{Conclusion}

This study contributes to the investigation of the effective functioning of the individual at work by considering experiences during non-work time. We showed that 
psychological detachment that fosters the restoration of depleted resources during a short respite plays a crucial role for work engagement. Likewise, high job involvement that promotes the investment of resources into work is of relevance for work engagement.

\section{Acknowledgements}

This study is part of Jana Kühnel's dissertation. This study was partly funded by the German Israeli Foundation (GIF; I 855 164.4/2003). This grant is gratefully acknowledged. We would like to thank Ronald Bledow, Carmen Binnewies, Anne Spychala, and anonymous reviewers for helpful comments on earlier versions of this paper.

\section{References}

Arbuckle, J. L. (2006). Amos user's guide (Version 7.0). Retrieved April, 2007, from http:// amosdevelopment.com

Aronsson, G., Svensson, L., \& Gustafsson, K. (2003). Unwinding, recuperation, and health among compulsory school and high school teachers in Sweden. International Journal of Stress Management, 10, 217234.

Bagozzi, R. P., \& Heatherton, T. F. (1994). A general approach to representing multifaceted personality constructs: Application to state self esteem. Structural Equation Modeling, 1, 3567.

Baron, R. M., \& Kenny, D. A. (1986). The moderator mediator variable distinction in social psychological research: Conceptual, strategic, and statistical considerations. Journal of Personality and Social Psychology, 51, 11731182.

Brosschot, J. F., Pieper, S., \& Thayer, J. F. (2005). Expanding stress theory: Prolonged activation and perseverative cognition. Psychoneuroendocrinology, 30, 10431049.

Brown, S. P., \& Leigh, T. W. (1996). A new look at psychological climate and its relationship to job involvement, effort, and performance. Journal of Applied Psychology, 81, 358368.

Browne, M. W., \& Cudeck, R. (1993). Alternative ways of assessing model fit. In K. A. Bollen \& J. S. Long (Eds.), Testing structural equation models (pp. 136 162). Newbury Park, CA: Sage.

Cheung, G. W., \& Lau, R. S. (2008). Testing mediation and suppression effects of latent variables: Bootstrapping with structural equation models. Organizational Research Methods, 11, 296325.

Cohen, A. (1998). An examination of the relationship between work commitment and work outcomes among hospital nurses. Scandinavian Journal of Management, 14, 117.

Craig, A., \& Cooper, R. E. (1992). Symptoms of acute and chronic fatigue. In A. P. Smith \& D. M. Jones (Eds.), Handbook of human performance (Vol. 3, pp. 289 339). London: Academic Press.

Dalal, R. S., Brummel, B. J., Wee, S., \& Thomas, L. L. (2008). Defining employee engagement for productive research and practice. Industrial and Organizational Psychology, 1, 5255.

Davis, J. A. (1998). The logic of causal order (Sage University Paper Series on Quantitative Applications in the Social Sciences, 07 055). Newbury Park, CA: Sage.

Demerouti, E., Bakker, A. B., de Jonge, J., Janssen, P. P. M., \& Schaufeli, W. B. (2001). Burnout and engagement at work as a function of demands and control. Scandinavian Journal of Work, Environment and Health, 27, 279286.

Eden, D. (2001). Vacations and other respites: Studying stress on an off the job. In C. L. Cooper \& I. T. Robertson (Eds.), International review of industrial and organizational psychology (Vol. 16, pp. 121 146). New York: Wiley.

Etzion, D., Eden, D., \& Lapidot, Y. (1998). Relief from job stressors and burnout: Reserve service as a respite. Journal of Applied Psychology, 83, 577585. 
Fritz, C., \& Sonnentag, S. (2005). Recovery, health, and job performance: Effects of weekend experiences. Journal of Occupational Health Psychology, 10, 187199.

Fritz, C., \& Sonnentag, S. (2006). Recovery, well being, and performance related outcomes: The role of workload and vacation experiences. Journal of Applied Psychology, 91, 936945.

Fritz, M. S., \& MacKinnon, D. P. (2007). Required sample size to detect the mediated effect. Psychological Science, 18, 233239.

Frone, M. R., Russell, M., \& Cooper, M. L. (1995). Job stressors, job involvement and employee health: A test of identity theory. Journal of Occupational and Organizational Psychology, 68, 111.

Geurts, S. A. E., \& Sonnentag, S. (2006). Recovery as an explanatory mechanism in the relation between acute stress reactions and chronic health impairment. Scandinavian Journal of Work, Environment and Health, 32, 482492.

González Romá, V., Schaufeli, W. B., Bakker, A. B., \& Lloret, S. (2006). Burnout and work engagement: Independent factors or opposite poles? Journal of Vocational Behavior, 68, 165174.

Hakanen, J. J., Bakker, A. B., \& Schaufeli, W. B. (2006). Burnout and work engagement among teachers. Journal of School Psychology, 43, 495513.

Hallberg, U. E., \& Schaufeli, W. B. (2006). 'Same same' but different? Can work engagement be discriminated from job involvement and organizational commitment? European Psychologist, $11,119127$.

Hobfoll, S. E. (1998). Stress, culture, and community: The psychology and philosophy of stress. New York, NY: Plenum Press

Hobfoll, S. E. (1989). Conservation of resources: A new attempt at conceptualizing stress. American Psychologist, 44, 513524.

Hobfoll, S. E. (2001). The influence of culture, community, and the nested self in the stress process: Advancing conservation of resources theory. Applied Psychology: An International Review, 50, 337370.

Holt, J. K. (2004, October). Item parceling in structural equation models for optimum solutions. Paper presented at the Annual Meeting of the Mid Western Educational Research Association, Columbus, $\mathrm{OH}$.

Judd, C. M., \& Kenny, D. A. (1981). Process analysis: Estimating mediation in treatment evaluations. Evaluation Review, 5, 602619.

Kahn, W. A. (1990). Psychological conditions of personal engagement and disengagement at work. Academy of Management Journal, 33, 692724.

Kanungo, R. N. (1979). The concept of alienation and involvement revisited. Psychological Bulletin, 86, 119138.

Kanungo, R. N. (1982). Measurement of job and work involvement. Journal of Applied Psychology, 67, 341349.

Kühnel, J. (2005). Erholungsaktivitäten, Gedanken an die Arbeit und Woblbefinden: Eine Tagebuch Studie mit Lebrerinnen und Lebrern. [Recovery activities, rumination and well being: A diary study with teachers] (Thesis). Freiburg, Germany, University of Freiburg.

Little, T. D., Cunningham, W. A., Shahar, G., \& Widaman, K. F. (2002). To parcel or not to parcel: Exploring the question, weighing the merits. Structural Equation Modeling, 9, 151173.

Macey, W. H., \& Schneider, B. (2008). Engaged in engagement: We are delighted we did it. Industrial and Organizational Psychology, 1, 7683.

MacKinnon D. P. (2003). Mediation FAQ. Retrieved January, 2008, from http://www.public.asu. edu/ davidpm/ripl/q\&a.htm\#q7

MacKinnon, D. P., Krull, J. L., \& Lockwood, C. M. (2000). Equivalence of the mediation, confounding and suppression effect. Prevention Science, 1, 173181.

Maslach, C., Schaufeli, W. B., \& Leiter, M. P. (2001). Job burnout. Annual Review of Psychology, 52,397422 . 
Meijman, T. F., \& Mulder, G. (1998). Psychological aspects of workload. In P. J. D. Drenth, H. Thierry, \& C. J. de Wolff (Eds.), Handbook of work and organizational psychology (Vol. 2, pp. 5 33). Hove, UK: Psychology Press.

Muraven, M., \& Baumeister, R. F. (2000). Self regulation and depletion of limited resources: Does self control resemble a muscle? Psychological Bulletin, 126, 247259.

Nunnally, J. C., \& Bernstein, I. H. (1994). Psychometric theory (3rd ed.). New York: McGraw Hill.

Paterson, J. M., \& O'Driscoll, M. P. (1990). An empirical assessment of Kanungo's (1982) concept and measure of job involvement. Applied Psychology: An International Review, 39, 293306.

Podsakoff, P. M., MacKenzie, S. B., Lee, J. Y., \& Podsakoff, N. P. (2003). Common method biases in behavioral research: A critical review of the literature and recommended remedies. Journal of Applied Psychology, 88, 879903.

Rabinowitz, S., Hall, T. H., \& Goodale, J. G. (1977). Job scope and individual differences as predictors of job involvement: Independent or interactive? Academy of Management Journal, 20, 273281.

Richardsen, A. M., Burke, R. J., \& Martinussen, M. (2006). Work and health outcomes among police officers: The mediating role of police cynicism and engagement. International Journal of Stress Management, 13, 555574.

Rothbard, N. P. (2001). Enriching or depleting? The dynamics of engagement in work and family roles. Administrative Science Quarterly, 46, 655684.

Salanova, M., Agut, S., \& Peiró, J. M. (2005). Linking organizational resources and work engagement to employee performance and customer loyalty: The mediation of service climate. Journal of Applied Psychology, 90, 12171227.

Schaufeli, W. B., \& Bakker, A. B. (2004). Job demands, job resources, and their relationship with burnout and engagement: A multi sample study. Journal of Organizational Behavior, 25, 293315.

Schaufeli, W. B., Bakker, A. B., \& Salanova, M. (2006). The measurement of work engagement with a short questionnaire: A cross national study. Educational and Psychological Measurement, 66,701716 .

Schaufeli, W. B., Salanova, M., González Romá, V., \& Bakker, A. B. (2002). The measurement of engagement and burnout: A two sample confirmatory factor analytic approach. Journal of Happiness Studies, 3, 7192.

Schaufeli, W. B., Taris, T. W., \& Bakker, A. B. (2006). Dr Jekyll or Mr Hyde? On the differences between work engagement and workaholism. In R. J. Burke (Ed.), Research companion to working time and work addiction (pp. 193 217). Northampton, MA: Edward Elgar Publishing.

Schaufeli, W. B., Taris, T. W., \& van Rhenen, W. (2008). Workaholism, burnout, and work engagement: Three of a kind or three different kinds of employee well being? Applied Psychology: An International Review, 57, 173203.

Shrout, P. E., \& Bolger, N. (2002). Mediation in experimental and nonexperimental studies: New procedures and recommendations. Psychological Methods, 7, 422445.

Sobel, M. E. (1982). Asymptotic intervals for indirect effects in structural equations models. In S. Leinhart (Ed.), Sociological methodology (pp. 290 312). San Francisco, CA: Jossey Bass.

Sonnentag, S. (2003). Recovery, work engagement, and proactive behavior: A new look at the interface between nonwork and work. Journal of Applied Psychology, 88, 518528.

Sonnentag, S., \& Bayer, U. V. (2005). Switching off mentally: Predictors and consequences of psychological detachment from work during off job time. Journal of Occupational Health Psychology, 10, 393414.

Sonnentag, S., \& Fritz, C. (2007). The recovery experience questionnaire: Development and validation of a measure for assessing recuperation and unwinding from work. Journal of Occupational Health Psychology, 12, 204221.

Sonnentag, S., \& Kruel, U. (2006). Psychological detachment from work during off job time: The role of job stressors, job involvement, and recovery related self efficacy. European Journal of Work and Organizational Psychology, 15, 197217. 
Thomsen, D. K., Mehlsen, M. Y., Christensen, S., \& Zachariae, R. (2003). Rumination relationship with negative mood and sleep quality. Personality and Individual Differences, 34 , 12931301.

Trougakos, J. P., Beal, D. J., Green, S. G. \& Weiss, H. M. (2008). Making the break count: An episodic examination of recovery activities, emotional experiences, and positive affective displays. Academy of Management Journal, 51, 131146.

Watson, D., Clark, L. A., \& Tellegen, A. (1988). Development and validation of brief measures of positive and negative affect: The PANAS scales. Journal of Personality and Social Psychology, $54,10631070$.

Westman, M. (1999, August). Gain and loss spirals: Applying Hobfoll's COR theory to respite research. Paper presented at the meeting of the Academy of Management. Chicago, IL.

Westman, M., \& Eden, D. (1997). Effects of a respite from work on burnout: Vacation relief and fade out. Journal of Applied Psychology, 82, 516527.

Westman, M., \& Etzion, D. (2001). The impact of vacation and job stress on burnout and absenteeism. Psychology and Health, 16, 595606.

Zohar, D., Tzischinsky, O., Epstein, R., \& Lavie, P. (2005). The effects of sleep loss on medical residents' emotional reactions to work events: A cognitive energy model. Sleep: Journal of Sleep and Sleep Disorders Research, 28, 4754.

Received 3 I August 2007; revised version received I August 2008 